Are specific initiatives required to enhance prescribing of generic atypical antipsychotics in Scotland; international implications?

\author{
M. Bennie MSc ${ }^{1,2}$, I. Bishop BSc${ }^{2}$, *B. Godman BSc, $\mathrm{PhD}^{3,4,5}$, C. Barbui MD ${ }^{6}$, Emanuel Raschi MD, \\ $\mathrm{PhD}^{7}$, S. Campbell $\mathrm{PhD}^{8}$, J Tellez MD, $\mathrm{PhD}^{9}$, LL Gustafsson MD,PhD ${ }^{3}$
}

${ }^{1}$ Strathclyde Institute for Pharmacy and Biomedical Sciences, University of Strathclyde, Glasgow, United Kingdom. Email: marion.bennie@strath.ac.uk

${ }^{2}$ Information Services Division, NHS National Services Scotland, Edinburgh, United Kingdom, EH12

9EB. Email: marion.bennie@nhs.net. Telephone: +44 131275 6432; Fax: +44 1312757606

2Email: iain.bishop@nhs.net. Telephone: +44 131275 6509. Fax: +44 1312757606

${ }^{3}$ Department of Laboratory Medicine, Division of Clinical Pharmacology, Karolinska Institutet,

Karolinska University Hospital Huddinge, SE-141 86, Stockholm, Sweden. Telephone + 468585810

68. Fax + 468585810 70. Email: Brian.Godman@ki.se. Email: lars-I.gustafsson@ki.se

${ }^{4}$ Institute for Pharmacological Research 'Mario Negri', Via Giuseppe La Masa 19, 20156 Milan, Italy.

Telephone +3902 39014314, Fax+39 02 354627. Email: godman@marionegri.it

${ }^{5}$ Prescribing Research Group, University of Liverpool Management School, Chatham Street,

Liverpool, UK L69 7ZH. Telephone +44 151795 3611, Fax +44 151795313

${ }^{6}$ WHO Collaborating Centre for Research and Training in Mental Health and Service Evaluation,

Department of Public Health and Community Medicine, Section of Psychiatry, University of Verona,

Policlinico G.B. Rossi, Piazzale L.A. Scuro 10, 37134 Verona, Italy. Tel +39- 0458126418 Fax +39 -

045 8027498. Email: corrado.barbui@univr.it

${ }^{7}$ Department of Medical and Surgical Sciences, Alma Mater Studiorum - University of Bologna,

Bologna, Italy. Email: Emanuel.raschi@unibo.it

${ }^{8}$ Primary Care Research Group, University of Manchester, United Kingdom M13 9PL. Telephone: +44

161275 7655. Email: stephen.campbell@manchester.ac.uk

${ }^{9}$ Department of Healthcare Development, Public Healthcare Services Committee Administration,

Stockholm County Council, Hantverkargatan 11B, plan 3, Stockholm, Sweden. Telephone: +46 8123

135 80. Email: jamilette.miranda-tellez@sll.se

*Author for correspondence

(Accepted International Journal Clinical Practice - Please keep CONFIDENTIAL)

\begin{abstract}
Background: National and regional authorities in Scotland have introduced multiple measures to appreciably enhance prescribing efficiency for the proton pump inhibitors (PPIs), statins and reninangiotensin inhibitor drugs. Generic oral risperidone recently became available in Scotland; however, schizophrenia is a complex disease with advice from respected authorities suggesting treatment should be individualised. Aims: Assess (i) changes in atypical antipsychotic (AAP) utilisation and expenditure following the availability of oral generic risperidone in Scotland, (ii) determine (a) current INN prescribing rates for risperidone following generic availability and (b) decrease in expenditure/ DDD for generic risperidone, (iii) suggest additional measures that could possibly be introduced in Scotland to further enhance prescribing of generic AAPs and (iv) provide guidance to NHS Scotland as well as other European authorities on the implications. Methods: Retrospective observational study and an interrupted time series design. Results: No appreciable change in the utilisation patterns of risperidone pre and post generic availability. Appreciable INN prescribing averaging $93 \%$ to $98 \%$ of total oral risperidone. Generic risperidone $84 \%$ below pre-patent loss prices by study end, reducing expenditure for risperidone in 2010 by GB£3.19mn compared with pre-patent loss situation. However, atypical expenditure increased overall by $42 \%$. Discussion: As expected, no change in utilisation patterns for risperidone although potential to influence prescribing patterns. Continued high INN prescribing suggests no problems with generic risperidone in practice. Costs will start to decrease as more atypicals lose their patents (olanzapine and quetiapine). Possibility to accelerate this through educational activities. Conclusion: Potential to realise some savings with AAPs. However, has been limited by complexity of disease area. Any measures introduced must aim at increasing the prescribing of generic AAPs first line in suitable patients.
\end{abstract}

Key words: Risperidone, generics, schizophrenia, reforms, drug utilisation studies, Scotland 


\section{'What's known?'}

- Multiple and intensive demand side measures are needed to successfully influence physician prescribing and appreciably enhance prescribing efficiency

- Schizophrenia is a complex disease area where limited differences in effectiveness between atypical antipsychotics (AAPs) apart from clozapine; however, differences in side-effects and response rates in individual patients. Consequently, greater tailoring of therapy than seen in other disease areas

- Opportunity to release resources with generic AAPs. Some concerns though with the effectiveness of generic AAPs versus originators

\section{'What's new?'}

- Greater need to tailor AAPs potentially limits the opportunity to release appreciable resources from generic AAPs if most still patent protected

- May be opportunities to instigate measures counteracting potential pressures from commercial organisations to enhance generic AAPs first line if no patient issues as AAP costs a high priority with now low costs of PPIs, statins and renin-angiotensin inhibitor drugs with generics

- High INN prescribing of risperidone once available as a generic suggests no real problems in practice

\section{Background}

Scrutiny on pharmaceutical expenditure has intensified among health authorities and health insurance companies across Europe in recent years, with its growth outstripping other components of ambulatory care expenditure [1-8]. As a result, pharmaceutical expenditure is now typically the largest or equalling the largest cost component in ambulatory care [1-4,6-8]. This growth will continue unless addressed, driven by well known factors including changing demographics, rising patient expectations and the continued launch of new expensive drugs [1-3,5-9].

These concerns have resulted in multiple reforms among European countries to improve the quality and efficiency of prescribing as resource pressures grow. Efficiency defined as utilisation increasing at a faster rate than expenditure in drug classes where all drugs are seen as similar in all or nearly all patients such as the proton pump inhibitors (PPIs), statins and renin-angiotensin inhibitor drugs [1$8,10-16]$. Multiple reforms for existing drugs include measures to obtain low prices for generics as well as enhance their utilisation versus originators and patented products in a class [1-8,10-18]. The objective being to conserve valuable resources as well as fund quality improvement programmes and new premium priced drugs $[5-8,13,14,16]$.

The UK, including Scotland, is no exception. Supply-side measures and initiatives for generics include the introduction of the ' $M$ ' and ' $W$ ' scheme to further lower the price of generics, which resulted in the prices of high volume generics being as low as $2 \%$ to $3 \%$ of pre-patent loss originator prices $[6,7,10,12,13,18,20,21]$. Examples of demand-side measures generally as well as for the PPIs in Scotland include physicians trained in medical school to prescribe by International Non-proprietary name (INN), national guidance and guidelines (SIGN) as well as regional formularies; monitoring of prescribing, 'Better Care Better Value' indicators to enhance the prescribing of low cost drugs versus patented drugs in a class or related class; practice based financial incentives as well as payment by results schemes $[5-8,13,16,19-21]$. These measures appreciably enhanced prescribing efficiency for high volume classes such as the PPs, e.g. reimbursed expenditure for PPIs in 2010 was $55 \%$ below 2001 levels despite a 3 fold increase in utilisation during this period (defined daily doses [DDD] basis - 100.2 DDD/ TID in 2010 - Thousand inhabitants per year), helped by increasing use of generic versus patented PPIs and expenditure/DDD for generic omeprazole in 2010 91\% below 2001 originator prices [16].

The utilisation of atypical antipsychotics has increased in recent years for the management of schizophrenia and bipolar disorders across Europe and the US [22-25]. This includes the UK where prescriptions for atypical antipsychotics in England rose from approximately $20 \%$ of all antipsychotic items in January to March 2000 to $67 \%$ in January to March 2007 [26]. The increase in prescribing of atypical antipsychotics appears to have been driven by meta-analyses and other studies suggesting greater efficacy and functional recovery as well as lower side-effects than typical antipsychotic drugs [23,27-29]. Alongside this, considerable increases in off-label use in recent years [30-34]. These 
clinical improvements resulted in reports of improved compliance and persistence for atypical antipsychotics, although others have not seen this in practice [35-37]. As a result, in June 2002, the National Institute for Health and Clinical Excellence (NICE) in the UK recommended the use of atypical (newer) oral antipsychotic drugs in people with newly diagnosed with schizophrenia and those currently taking typical (older) antipsychotic drugs where their symptoms are being controlled but there are side effects with these drugs [38]. NICE recently updated its guidance for patients with newly diagnosed schizophrenia offered oral antipsychotic medication [39], stating that healthcare professionals should 'provide information and discuss the benefits and side-effect profile of each drug with the service user. The choice of drug should be made by the service user and healthcare professional together, considering:

- the relative potential of individual antipsychotic drugs to cause extrapyramidal side effects (including akathisia), metabolic side effects (including weight gain) and other side effects (including unpleasant subjective experiences)

- the views of the carer where the service user agrees'

NICE also suggested that for people with schizophrenia whose illness has not responded adequately to pharmacological or psychological treatment healthcare professionals should [39]:

- review the diagnosis

- establish that there has been adherence to antipsychotic medication, prescribed at an adequate dose and for the correct duration

- review engagement with and use of psychological treatments and ensure that these have been offered according to this guideline. If family intervention has been undertaken suggest cognitive behavioural therapy (CBT); if CBT has been undertaken suggest family intervention for people in close contact with their families

- consider other causes of non-response, such as comorbid substance misuse (including alcohol), the concurrent use of other prescribed medication or physical illness

In addition, physicians should offer clozapine to people with schizophrenia whose illness has not responded adequately to treatment despite the sequential use of adequate doses of at least two different antipsychotic drugs. At least one of the drugs should be a non-clozapine second-generation antipsychotic [39].

However, there have been concerns about the quality of the evidence and the extent of the differences in practice in the effectiveness of typical versus atypical antipsychotics [38]. This especially with growing criticism that high-potency haloperidol (typical antipsychotic) was used as a comparator in the studies with second generation (atypical antipsychotics) thereby biasing the results, and only a limited number of studies used medium-potency first generation (typical) antipsychotics as the comparator $[35,36]$. Alongside this, greater levels of side-effects such as weight gain, hyperlipidaemia and Type 2 diabetes with atypical antipsychotics [22,39-41]. In addition, the risk of QT prolongation and subsequent arrhythmia-related events, i.e. Torsade de Pointes (TdP) and Sudden Cardiac Death, is being increasingly seen as one of the most important safety aspect to consider when patients are prescribed atypical antipsychotic drugs $[44,45]$. In the past, atypical antipsychotic drugs have been perceived as generally having a favourable cardiac safety profile compared with typical antipsychotic drugs. However, these beliefs have been undermined by a recent cohort study finding a dose-dependent increased risk of sudden cardiac deaths among current users [46], further corroborated by different case series [47] as well as pharmacovigilance analyses $[48,49]$, showing similar reporting ratios between typical and atypical antipsychotic drugs in clinical practice. Tiihonen and colleagues have also recently shown that the highest risk of mortality in patients with schizophrenia prescribed atypical antipsychotic drugs compared to pherphenazine was seen with quetiapine with the lowest with clozapine [50]. Haloperidol and risperidone slightly lower adjusted hazard ratios than quetiapine [50]. In June 2008, the FDA also notified healthcare professionals that both typical (conventional) and atypical antipsychotics are associated with an increased risk of mortality in elderly patients treated for dementia-related psychosis (unlabeled indication) [51].

These debates have continued with the publication of the various findings from the Clinical Antipsychotic Trials of Intervention Effectiveness (CATIE) study in the US showing limited differences between the various antipsychotics, although this is not without criticism [22,52-54]. The various studies suggest that 'the numerous antipsychotic drugs, however they might be classified, are more similar to than different from each other. To the extent that antipsychotics differ, it is more in their side effects than therapeutic effects. Nevertheless, there is variation in the effectiveness of antipsychotic 
drugs, which for individual patients can be substantial, and what works for one person may not work for another. Consequently, treatments for schizophrenia must be individualized' [53]. Recent reviews by the Cochrane Collaboration and others would suggest that olanzapine may be a somewhat more efficacious than some other second generation antipsychotic drugs, with mixed results with risperidone. However, these conclusions are tentative due to the large dropout rates in most studies [55-58]. In addition, re-analysis of the CATIE study suggests that unless the clinical situation requires a medication change, it may be best for patients to optimise current medication regimens rather than switching medications with no apparent gains with switching therapies $[59,60]$.

Other authors though believe the modest gains with atypical antipsychotic drugs that have reported do not adequately reflect the improvements in quality of life perceived by patients, clinicians or carers [61]. This may be important especially with family support appearing to make a difference with outcomes in practice [62].

In any event, utilisation of atypical anti-psychotic drugs continues to increase, which is likely to remain [22-26]. Consequently, the availability of generic atypical antipsychotics should be welcomed by health authorities in the UK where initiatives to lower prices for generics, coupled with high INN prescribing rates, has led to low prices for generics [5,6, 14-16]. The first atypical antipsychotic drug to become available as a generic in the UK was clozapine, with published studies, including those from the UK, showing no difference in outcomes between the originator and generics in practice once initial the problems in the US had been resolved [22,63-66]. More recently, generic olanzapine and generic risperidone have become available across Europe with again no apparent patient issues in practice $[18,22,67,68]$, although some are more cautious [68,69].

It is recognised though that schizophrenia and other conditions such as bipolar disorders are more complex to treat than stomach related acid disorders, hypercholesterolaemia or hypertension. In addition as documented, atypical antipsychotic drugs should not be considered as one class containing similar products unlike the PPIs, statins or renin-angiotensin drugs $[3,5-8,10,11,14-17,70]$ As a result, greater necessity for tailoring treatments depending on the patient and their characteristics having considered the safety profile of the drug, e.g. olanzapine should not be considered in young ladies with weight problems or risperidone in patients with sexual problems. In addition, switching should only be considered if patients are failing on their current treatment, or having undue side-effects from their current treatment, having considered that it may be best for patients to optimise current medication regimens before switching $[59,60]$. Having said this, there may be a number of patients who could be started on a number of different antipsychotic drugs. In this situation, it would be sensible for physicians to start patients on a generic atypical antipsychotic, which is the advice given by NICE and Lothian Health Board [39,71,72]. Alongside this enhancing the utilisation of generic oral tablets versus patented premium priced orodispersible tablets [72].

Consequently, the availability of oral generic risperidone versus patented olanzapine, quetiapine, aripiprazole and zotepine, should in theory lead to increased prescribing of risperidone first line among patients where there are a number of treatment options. This building on general initiatives in Scotland to enhance the prescribing of generics, e.g. a Hawthorne effect [73-76], especially as olanzapine and quetiapine were among the ten highest expenditure drugs in Scotland in 2010 [77].

\section{Aims}

The principal aim is to assess the changes in atypical antipsychotic drug utilisation and expenditure patterns in Scotland following the availability of oral generic risperidone in April 2008. In addition (a) determine current INN prescribing rates for risperidone following generic availability, (b) the decrease in expenditure/ DDD for generic risperidone versus pre-patent loss prices over time and compare these with the situation seen with generic PPIs and statins, (c) suggest additional measures that could possibly be introduced in Scotland to further enhance the prescribing of generic atypical antipsychotics given the complexities of the situation, (d) provide guidance to NHS Scotland as well as other European health authorities and health insurance companies on the implications of the findings. 


\section{Methodology}

Two methodologies were utilised. The first involved a retrospective observational study of the utilisation and reimbursed expenditure in the administrative database of NHS National Services Scotland Corporate Warehouse of all patients in Scotland dispensed at least one atypical antipsychotics (Olanzapine - N05AH03, quetiapine - N05AH04, amisulpride - N05AL05, risperidone - N05AX08, zotepine - N05AX11, aripiprazole - N05AX12 and paliperidone - N05AX13) between 2005 and 2010, i.e. 2 full years before the availability of oral generic risperidone in April 2008 and two full years after $[78,79]$. Clozapine was not included in this analysis as this is reserved for resistant patients due to its side-effect profile [22,23, 28,63,65,80-82]. Asenepine (N05AH05) and clotiapine (N05AH06) were never reimbursed in Scotland; consequently, also not included in the analysis.

The second study was an interrupted time series design to analyse the changes in monthly reimbursed prescriptions in the administrative database of NHS National Services Scotland Corporate Warehouse of all patients in Scotland dispensed at least one atypical antipsychotic (N05AH03 to 05, N05AL05, N05AX08,11 to 13) between April 2006, i.e. 2 years before oral generic risperidone was reimbursed, to September 2011 some 41 months after oral generic risperidone was reimbursed.

The two methodologies were chosen to provide different data sets. The monthly data will help demonstrate more visibly any ongoing changes in atypical antipsychotic utilisation patterns before and after the availability of oral generic risperidone. The yearly data will help assess overall changes in expenditure patterns for comparison with other drug classes. All comparator data with other classes has been taken from previously published studies of Scotland by the co-authors (MB, IB, SC, BBG).

Utilisation was collated in terms of DDDs, with DDDs defined as 'the average maintenance dose of a drug when used in its major indication in adults', as this measure is recognised as the international standard to assess utilisation patterns within and between countries [78,79]. 2011 DDDs were used in line with international guidance $[5-8,79,83]$.

Serial autocorrelations of risperidone DDDs were assessed in the interrupted time series design using an ARIMA model and a Box-Jenkins-Tiao strategy [84]. DDDs were plotted over time in months. The graphs were visually inspected to assess the trends or the nonstationarity of the data. Alongside this, a segmented regression analysis of the interrupted time series was used to assess the effect of the availability of generic risperidone in April 2008 on its subsequent utilization versus other atypical antipsychotics. Common segmented regression models were used to fit a least-squares regression line to each segment of the independent variable (time $t$ ), assuming a linear relationship between time and the outcome within each segment. The effect of the intervention (generic risperidone) was assessed with using the model: $Y_{t}=\beta_{0}+\beta_{1}\left(\right.$ time $_{t=0,1,2, \ldots, 24)}+\beta_{2}$ (intervention $\left.1 t\right)+\beta_{3}$ (time after intervention $1 t)+\beta_{4} \beta_{2}$ (intervention $\left.2 t\right)+\beta_{5}$ (time after intervention $\left.2 t\right)+e_{t}$, where $Y_{t}$ was risperidone DDDs per month $t$, time is a continuous variable indicating time (in months) at time $t$ from the start until the end of the observation period, intervention is an indicator variable for time $t$ occurring before ( $t=0$ month) or after ( $t=1$ month) reimbursement of generic risperidone, and $e_{t}$ is the error term at time $t$ [85]. The time after reimbursement (months) is a continuous variable that counts the number of months after the intervention at time $t$, coded time 0 before the intervention (April 2008). The DurbinWatson statistic was calculated to test for a serial autocorrelation of the error terms in the regression models [86]. The statistical package IBM SPSS Statistics version 19.0 was used for all analyses. A $P$ value of $<0.05$ was considered significant [87].

We are confident we can undertake this type of analysis as there were no major demand-side measures instigated across Scotland in direct response to the availability of generic risperidone apart from the formulary guidance of Lothian Health Board in recent years [72].

Reimbursed expenditure was used as these are the costs incurred by NHS Scotland, which is the perspective of the paper. This is in line with previous studies, and facilitates comparisons with other countries $[5-8,12,14,16]$. There has been no allowance for inflation as typically health authorities throughout Europe seek to reduce drug prices if expenditure for pharmaceuticals is rising more rapidly than agreed amounts $[1-3,5,7,8,88]$. In addition, introduce measures to lower the price for generics over time $[1-6,8,14,17,22]$. Scotland is no exception $[6-8,16]$. 


\section{Results}

There was a $53 \%$ increase in the utilisation of atypical antipsychotic drugs during the course of the study, rising from 3.4DDD/ TID in 2005 to 5.1 in 2010, driven by increasing utilisation of olanzapine, quetiapine and aripiprazole (Figure 1).

Figure 1 - DDD/ TID for atypical antipsychotic drugs in Scotland 2005 to 2010

\section{Generic oral risperidone}

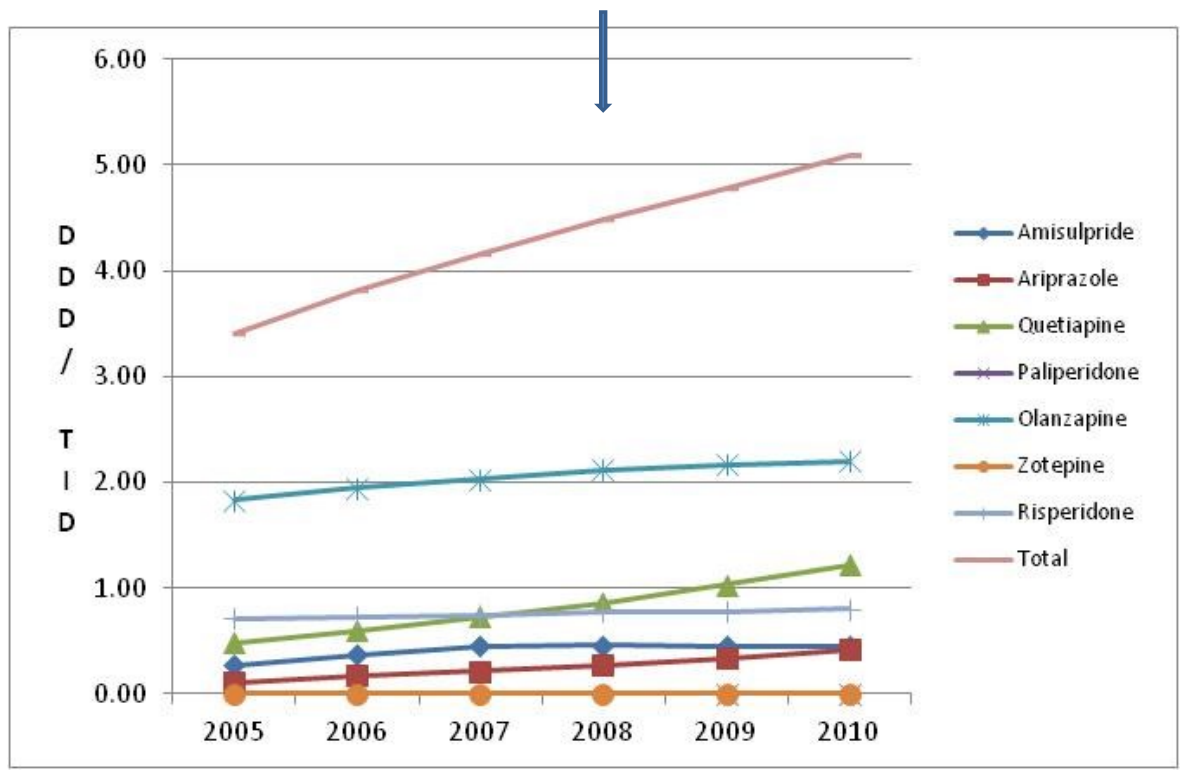

As a result, the utilisation of risperidone as a \% of total DDDs for the atypical anti-psychotics decreased steadily from $21 \%$ in 2005 to $16 \%$ in 2010 (Figure 2). However, during this period the utilisation of long-acting risperidone injections increased from $3.8 \%$ of total risperidone (DDD basis) in 2005 to $6.5 \%$ in 2010 . 
Figure 2 - \% utilisation of different atypical anti-psychotics (DDD basis) 2005 to 2010

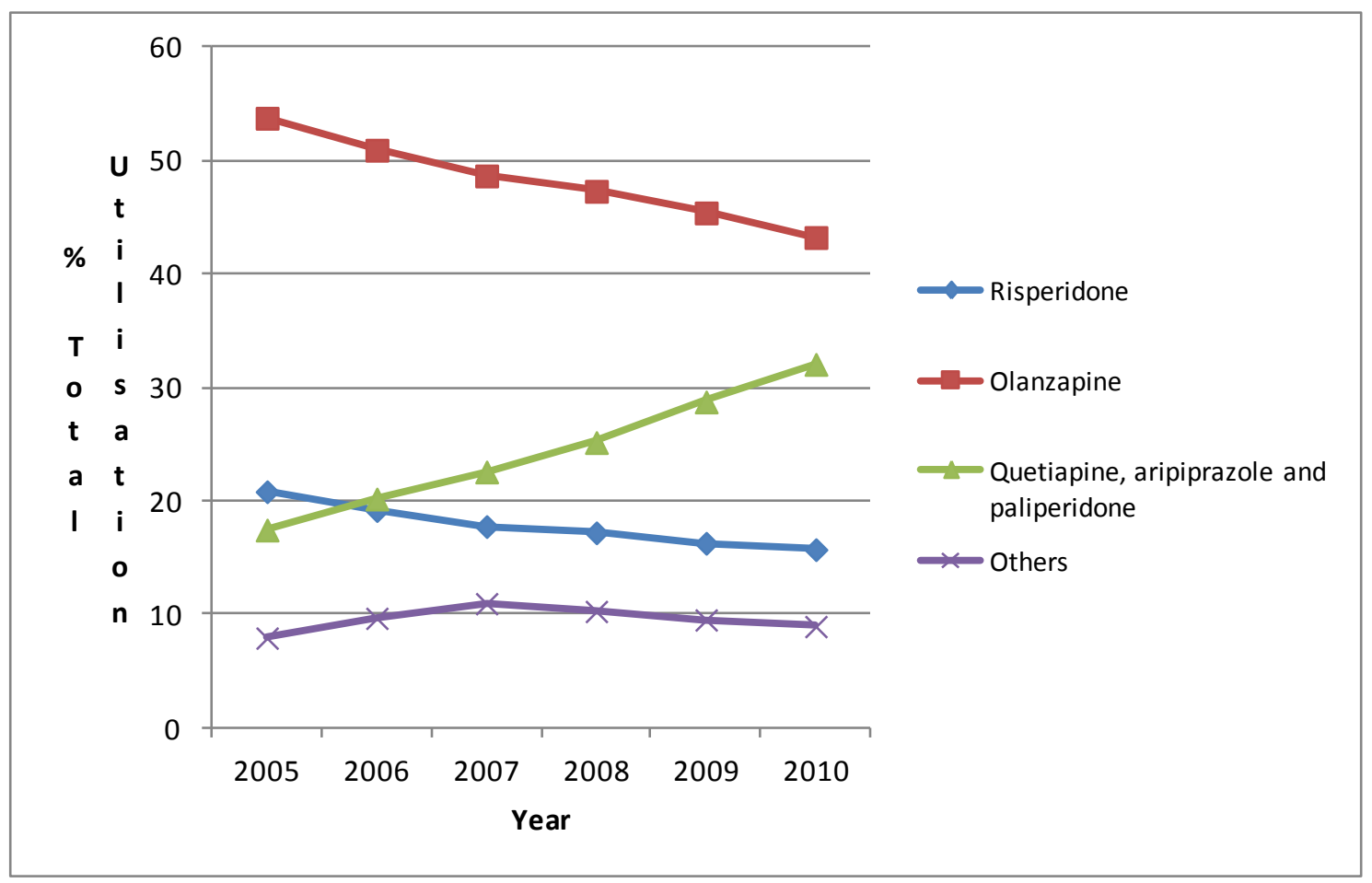

There was high utilisation of oral generic risperidone, with INN prescribing averaging $93 \%$ to $98 \%$ of total oral risperidone on a DDD basis following the availability of generics.

The monthly DDD utilisation data also showed no change in overall utilisation patterns for risperidone versus other atypical antipsychotics before and after the availability of generic risperidone (Figures 3 and 4, Table 1), with any increase in the utilisation of risperidone mirroring the increase in the utilisation of atypical antipsychotic drugs generally. However, the rate of increase was lower as demonstrated by decreasing utilisation of risperidone versus all atypical antipsychotic drugs since the availability of generic risperidone. 
Figure 3 - Monthly DDDs for atypical in Scotland April 2006 to September 2011

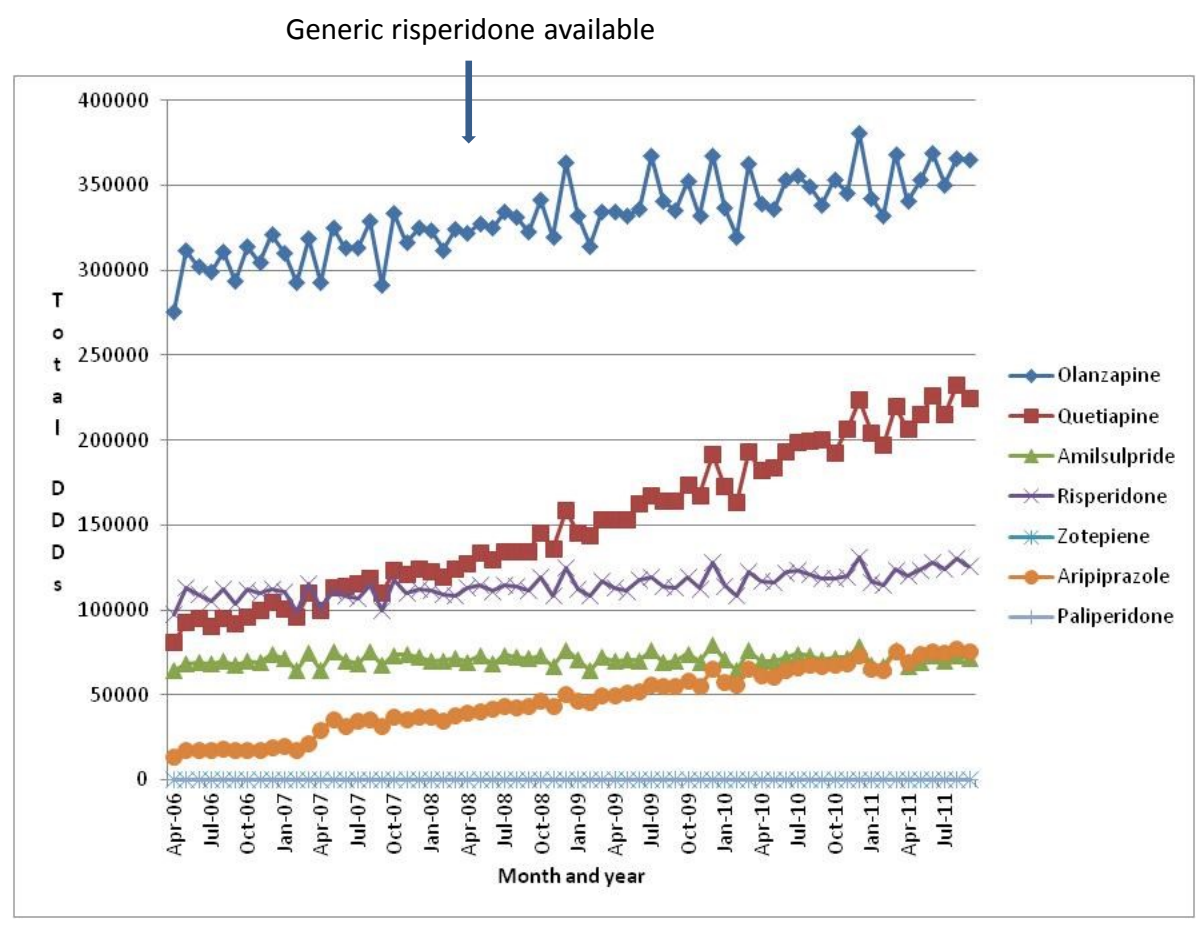

Table 1 - Parameter estimates, standard errors and P-values from the segmented regression model predicting the extent of risperidone DDDs before and after generic risperidone (Coefficient variable is risperidone DDDs)

\begin{tabular}{|c|c|c|c|c|c|c|c|c|}
\hline \multicolumn{9}{|c|}{ Coefficients $^{a}$} \\
\hline \multirow{2}{*}{\multicolumn{2}{|c|}{ Model }} & \multicolumn{2}{|c|}{ Unstandardized Coefficients } & \multirow{2}{*}{$\begin{array}{l}\text { Standardized } \\
\text { Coefficients } \\
\text { Beta }\end{array}$} & \multirow[b]{2}{*}{$t$} & \multirow[b]{2}{*}{ Sig. } & \multicolumn{2}{|c|}{$95.0 \%$ Confidence Interval for B } \\
\hline & & $\mathrm{B}$ & Std. Error & & & & Lower Bound & Upper Bound \\
\hline \multirow[t]{4}{*}{1} & (Constant) & 106768.517 & 2051.570 & & 52.042 & .000 & 102667.486 & 110869.547 \\
\hline & Time & 156.516 & 143.580 & .415 & 1.090 & .280 & -130.497 & 443.528 \\
\hline & Reimbursement & 900.263 & 2460.617 & .060 & .366 & .716 & -4018.440 & 5818.967 \\
\hline & Time after reimbursement & 151.781 & 156.388 & .299 & .971 & .336 & -160.835 & 464.397 \\
\hline
\end{tabular}

a. Dependent Variable: Risperidone DDDs 
Figure 4 - Change in utilization patterns for risperidone (DDDs reimbursed) over time before and after generic risperidone

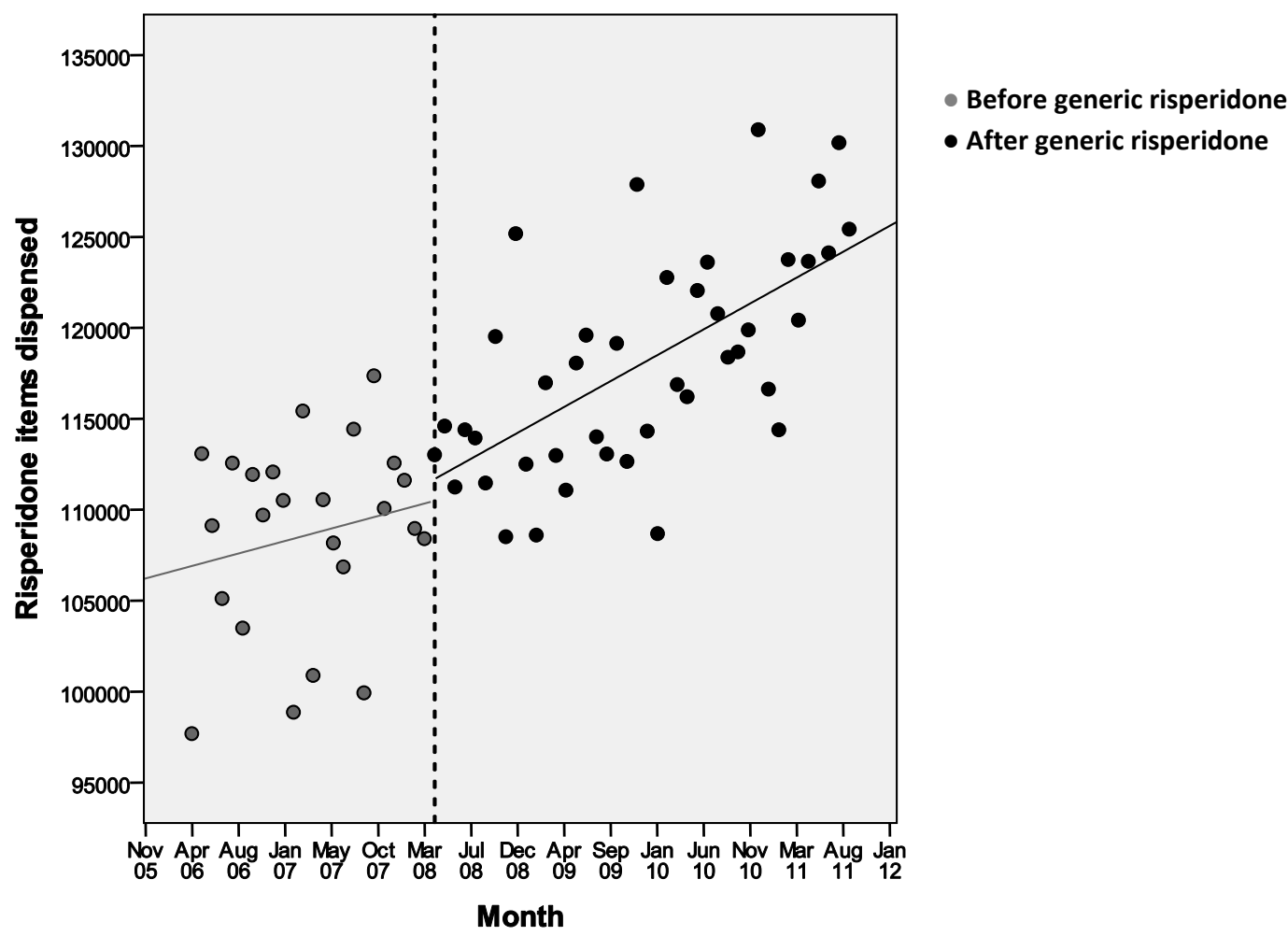

Reimbursed expenditure for atypical antipsychotics grew by $42 \%$ during the study period, increasing from $£ 4662 / 1000$ inhabitants/year in 2005 to $£ 6512 / 1000$ inhabitants/year in 2010. This increase was lower than the increase in utilisation, facilitated by reimbursed expenditure/ DDD for generic oral risperidone at GB£0.47p in 2010, $84 \%$ below pre-patent loss prices. This reduction in expenditure/ DDD for generic oral risperidone reduced expenditure for risperidone in 2010 by GB£3.19mn compared with the pre-patent loss situation.

\section{Discussion}

As expected, there was no appreciable change in the utilisation pattern for risperidone versus other atypical antipsychotics following the availability of generic risperidone (Figures 3 and 4, Table 1). This may well reflect the advice from NICE and the conclusions of the various Cochrane reviews and CATIE studies that treatments should be tailored to the individual $[39,41,42,53-56]$ as schizophrenia and bipolar disease are far more complex to treat than those treated with the PPIs, statins, ACEls or ARBs. Consequently, no apparent Hawthorne effect [73-76]. However, this will need further research before any definite conclusions can be drawn especially with the growing utilisation of the patented atypical antipsychotic drugs (quetiapine and aripiprazole) during the study period, reducing utilisation of risperidone as a \% of atypical antipsychotic drugs (Figures 1 and 2), and substantial fines for Johnson and Johnson and AstraZeneca in the US for inappropriate marketing activities [31-34]. The off-label utilisation of atypical antipsychotics requires close monitoring by the regulatory and health authorities in view of the limited clinical benefit of atypical antipsychotic drugs in some patients coupled with potentially life-threatening events $[30,89]$.

As a result, there may be opportunities for Health Board personnel to work with psychiatrists to see whether there could be more patients started on generic atypical antipsychotic drugs where choices 
are available having considered all the potential side-effect issues. This may now become easier with oral olanzapine losing its patent at the end of 2011 and quetiapine in March 2012 [I. Bishop Personal communication]. Both situations should appreciably reduce reimbursed expenditure for the atypical antipsychotics in Scotland as they are the most prescribed ones (Figures 1 and 3), and we have already seen a considerable reduction in expenditure/ DDD for generic risperidone. This will be welcomed as expenditure/ 1000 inhabitants/year for atypical antipsychotics in Scotland in 2010 was already higher than expenditure for the PPIs despite appreciably lower utilisation rates at 5.1 DDD/ TID versus 100.2 for the PPIs [16]. In addition, reimbursed expenditure/ 1000 inhabitants/ year for the statins in 2010 was only $75 \%$ higher than that for the atypical antipsychotic drugs in 2010 despite utilisation rates of over 140DDD/ TID for the statins. Any activities though must be carefully considered in view of more atypical antipsychotic drugs becoming available as generics and any activities undertaken would divert attention from already agreed quality and efficiency initiatives in Scotland in 2012 [90]. This especially if more sophisticated analyses are undertaken with patient databases rather than consolidated drug utilisation databases such as exploring current and future atypical antipsychotic drug sequencing. This is a possibility in Scotland with its sophisticated databases linking ambulatory and secondary care. We recognised this is a limitation of the current study methodology, which we will be looking to address in further research. However, in the meantime we believe our findings are of interest to other countries.

One area though for further analysis is the increasing utilisation of long-acting risperidone injections (RLAl) as a percentage of total risperidone. This is in view of its considerably higher price on an expenditure/ DDD versus generic oral risperidone, and ongoing concerns regarding its increased efficiency in practice given that most of the published studies with RLAl are open label and subject to sponsor bias coupled with a number of independent randomised and observational studies showing no benefit versus oral treatments [91-98]. This will now be looked at further within NHS Scotland.

We believe an important finding was the high INN prescribing of oral risperidone during the study period with community pharmacists in the UK not allowed to substitute an originator for a generic if the physician prescribes the originator. This suggests no perceived problems with oral generic risperidone in Scotland during the considerable time period when it has been available, mirroring other countries $[18,22]$. This will help address some of the concerns voiced about the quality and effectiveness of generic atypical antipsychotics $[18,22,64,65]$. High INN prescribing also reduces any patient confusion that can exist in countries with branded generics $[4,14,16]$, which is likely to be beneficial in this patient population. Both these points are important for health authorities and health insurance agencies seeking to increase their utilisation of generic atypical antipsychotics to conserve valuable resources without compromising care, given current high expenditures on atypical antipsychotic drugs.

Low prices for generic risperidone versus pre-patent loss prices also mirrors the situation seen with generic omeprazole and generic simvastatin in the UK $[5,8,14,16]$. The savings from the availability of oral generic risperidone will be enhanced with envisaged further reductions in expenditure/ DDD of risperidone over time, mirroring the situation for other generics in the UK $[14,16]$.

In conclusion, it is difficult to transfer the multiple demand-side measures used to enhance prescribing efficiency for the PPIs, statins and renin-angiotensin drugs to complex disease areas such as schizophrenia, especially with the atypical antipsychotic drugs not considered as interchangeable coupled with physicians tending to individualise treatment depending on the patient. However, there may be opportunities to enhance the prescribing of generic atypical antipsychotics first line if multiple choices are available with educational and other demand-side measures to counteract commercial company activities. Such activities could also help reduce off-label use of atypical antipsychotic drugs where this is considered an issue. On a positive note, there appears to be no problems with generic risperidone in Scotland as seen by the continued high INN prescribing rates. This should be welcomed by authorities across Europe. 


\section{Financial disclosure and acknowledgements}

MB and IB are employed by NHS Scotland. The authors have no other conflicts of interest to declare.

This work was in part supported by grants from the Karolinska Institutet, Sweden.

No writing assistance was provided for this paper.

\section{References}

1. Godman B, Bucsics A, Burkhardt T, Haycox A, Seyfried H, Wieninger P. Insight into recent reforms and initiatives in Austria; implications for key stakeholders. Expert Rev Pharmacoeconomcis Outcomes Research 2008; 8:357-371

2. Sermet C, Andrieu V, Godman B, Van Ganse E, Haycox A, Reynier JP. Ongoing pharmaceutical reforms in France; implications for key stakeholder groups. Applied Health Economics and Health Policy 2010;8:7-24

3. Coma A, Zara C, Godman B, Augusti A, Diogene E, Wettermark B, Haycox A. Policies to enhance the efficiency of prescribing in the Spanish Catalan Region: impact and future direction. Exp Review of Pharmacoeconomics and Outcomes Research 2009; 9: 569-81

4. Wettermark B, Godman B, Andersson K, Gustafsson LL, Haycox A, Bertele' V. Recent national and regional drug reforms in Sweden - implications for pharmaceutical companies in Europe. Pharmacoeconomics 2008; 26: 537-50

5. Godman B, Shrank W, Wettermark B, Andersen M, Bishop I et al. Use of generics - a critical cost containment measure for all healthcare professionals in Europe? Pharmaceuticals 2010; 3:247094 doi 10.3390/ph/3082470 ISSN 1424-8247

6. Vončina L, Strizrep T, Godman B, Bennie M, Bishop I, Campbell S, Vlahovic Palcevski V, Gustafsson LL. Influence of demand side measures to enhance renin-angiotensin prescribing efficiency in Europe; implications for the future. Expert Rev Pharmacoeconomics and Outcomes Res 2011; 11: 469-79

7. Godman B, Shrank W, Andersen M, Berg C, Bishop I, Burkhardt T et al. Comparing policies to enhance prescribing efficiency in Europe through increasing generic utilisation: changes seen and global implications. Expert Rev. Pharmacoeconomics Outcomes Res 2010; 10: 707-22

8. Godman B, Shrank W, Andersen M, Berg C, Bishop I, Burkhardt T, Garuoliene K et al. Policies to enhance prescribing efficiency in Europe: findings and future implications. Frontiers Pharmacol. 2011; 1 (141): 1-16 doi: 10.3389/fphar.2010.00141

9. Garattini S, Bertele V, Godman B, Haycox A, Wettermark B, Gustafsson LL. Enhancing the rational use of new medicines across European healthcare systems - A Position Paper. Eur Jn Clinical Pharmacology 2008; 64:1137-8

10. Godman B, Haycox A, Schwabe U et al. Having your cake and eating it: Office of Fair Trading proposal for funding new drugs to benefit patients and innovative companies.

Pharmacoeconomics 2008; 26:91-98

11. Norman C, Zarrinkoub R, Hasselström J, Godman B, Granath F, and Wettermark B. Potential savings without compromising the quality of care. Int J Clin Pract 2009: 63:1320-26

12. Godman B, Sakshaug S, Berg C, Wettermark B, Haycox A. Combination of prescribing restrictions and policies to engineer low prices to reduce reimbursement costs. Expert Rev. Pharmacoeconomics Outcomes Res. 2011; 11: 121-9

13. Godman B, Malmstrom RE, Bennie M, Sakshaug S, Burkhardt et al. Prescribing restrictions - a necessary strategy among some European countries to enhance future prescribing efficiency? Reviews in Health Care 2012; 3: 5-16

14. McGinn D, Godman B, Lonsdale J, Way R, Wettermark B, Haycox A. Initiatives to enhance the quality and efficiency of statin and PPI prescribing in the UK; impact and implications. Expert Rev Pharmacoeconomics and Outcomes Res 2010; 10: 73-85

15. Gustafsson LL, Wettermark B, Godman B, Andersén-Karlsson E, Bergman U et al. The "Wise List"- A comprehensive concept to select, communicate and achieve adherence to recommendations of essential drugs in ambulatory care in Stockholm. Basic \& Clinical Pharmacology \& Toxicology 2011; 108:224-233

16. Bennie M, Godman B, Bishop I, Campbell S. Multiple initiatives continue to enhance the prescribing efficiency for the proton pump inhibitors and statins in Scotland. Expert Review Pharmacoeconomics and Outcomes Research 2012; 12: 125-130 
17. Garuoliene K, Godman B, Gulbinovič J, Wettermark B, Haycox A. European countries with small populations can obtain low prices for drugs: Lithuania as a case history. Expert Rev. Pharmacoeconomics Outcomes Res 2011; 11: 343-9

18. Araszkiewicz AA, Szabert K, Godman B, Wladysiuk M, Barbui C, Haycox A. Generic olanzapine: health authority opportunity or nightmare? Expert Rev Pharmacoeconomics Outcomes Res 2008; 8:549-55

19. SIGN. Dyspepsia - a national clinical guideline. March 2003. Available via URL: http://www.sign.ac.uk/pdf/sign68.pdf [Accessed 10 November 2011]

20. SIGN. Secondary prevention of CHD following Myocardial Infarction. 2000. Available via URL: http://www.nhsggc.org.uk/content/mediaassets/pdf/HSD/sign41.pdf [Accessed 13 Nov 2011

21. SIGN. Management of Diabetes. 2001 Available via URL: http://www.sign.ac.uk/pdf/grg55.pdf [Accessed 13 Nov 2011]

22. Wladysiuk M, Araszkiewicz A, Godman B, Szabert K et al. Patient co-payments do influence atypical antipsychotic choice in Poland; implications once generic atypcials are available. Appl Health Econ Health Policy. 2011; 9: 101-10

23. Knapp M, Kanavos P, King D, et al. Economic issues in access to medications: schizophrenia treatment in England. Int J Law Psychiatry 2005; 28: 514-31

24. Mirandola M, Andretta M, Corbari L, et al. Prevalence, incidence and persistence of antipsychotic drug prescribing in the Italian general population: retrospective database analysis, 1999-2002. Pharmacoepidemiol Drug Saf 2006; 15: 412-20

25. Crystal S, Olfson M, Huang C, et al. Broadened use of atypical antipsychotics: safety, effectiveness, and policy challenges. Health Aff 2009; 28 (5): 770-81

26. NICE implementation uptake report: atypical antipsychotic drugs for the treatment of schizophrenia. NICE Technology appraisals 43. Available via URL: http://www.nice.org.uk/media/410/E9/ImplUptakeReportAtypicalAntipsychotics.pdf

27. Mond J, Morice R, Owen C, et al. Use of antipsychotic medications in Australia between July 1995 and December 2001. Aust N Z J Psychiatry 2003; 37: 55-61

28. Leucht $S$, Corvers $C$, Arbter $D$, et al. Second-generation versus first-generation antipsychotic drugs for schizophrenia: a meta-analysis. Lancet 2009; 373 (9657): 31-41

29. Kishimoto T, Agarwal V, Kishi T, Leucht S, Kane JM, Correll CU. Relapse prevention in schizophrenia: a systematic review and meta-analysis of second-generation antipsychotics versus first-generation antipsychotics. Mol Psychiatry. 2011 Nov 29. doi: 10.1038/mp.2011.143. [Epub ahead of print]

30. Alexander GC, Gallagher SA, Mascola A, Moloney RM, Stafford RS. Increasing off-label use of antipsychotic medications in the United States, 1995-2008. Pharmacoepidemiol Drug Saf. 2011;20:177-84

31. Leslie D, Rosenheck R. Off-Label Use of Antipsychotic Medications in Medicaid. Am J Manag Care. 2012;18(3):e109-e117

32. Fisk M, Feeley J, Voreacos D. J\&J Said to Agree to $\$ 2.2$ Billion Drug Marketing Accord. Available via URL: (http://www.bloomberg.com/news/2012-06-11/j-j-said-to-pay-2-2-billion-to-end-risperdalsales-probe.html [Accessed 18 September 2012]

33. Department of Justice settlement agreement. Available via URL: http://www.justice.gov/usao/pae/Pharma-Device/astrazeneca settlementagreement.pdf [Accessed 18 September 2012]

34. Jack A. AstraZeneca faces $\$ 520 \mathrm{~m}$ Seroquel fine. Available via URL: http://www.ft.com/cms/s/0/319e31d4-5251-11df-8b09-00144feab49a.htm|\#axzz26q1gMSgc [Accessed 18 September 2012]

35. Ren XS, Qian S, Lee AF, et al. Treatment persistence: a comparison among patients with schizophrenia who were initiated on atypical antipsychotic agents. J Clin Pharm Ther 2006; 31: 57-65

36. Taylor DM, Wright T, Libretto S. Risperidone compared with olanzapine in a naturalistic clinical study: a cost analysis. J Clin Psychiatry 2003; 64: 589-97

37. Valenstein M, Blow FC, Copeland LA, et al. Poor antipsychotic adherence among patients with schizophrenia: medication and patient factors. Schizophr Bull 2004; 30: 255-64

38. Walley T. Neuropsychotherapeutics in the UK. What has been the impact of NICE on prescribing? CNS Drugs 2004; 18 (1): 1-12

39. NICE. Schizophrenia - Core interventions in the treatment and management of schizophrenia in adults in primary and secondary care. NICE ClinicalGuideline 82. Issued March 2009. Available via URL: http://www.nice.org.uk/nicemedia/live/11786/43610/43610.pdf 
40. Leucht S, Wahlbeck K, Hamann J, et al. New generation antipsychotics versus low-potency conventional antipsychotics: a systematic review and meta-analysis. Lancet 2003; 361 (9369): $1581-9$

41. Tyrer $P$, Kendall $T$. The spurious advance of antipsychotic drug therapy. Lancet 2009; 373 (9657): 4-5

42. Gardner D, Baldessarini RJ, Waraich P. Modern antipsychotic drugs: a critical overview. CMAJ 2005; 172 (13): 1703-11

43. Andretta M, Ciuna A, Corbari L, et al. Impact of regulatory changes on first- and secondgeneration antipsychotic drug consumption and expenditure in Italy. Soc Psychiatry Psychiatr Epidemiol 2005; 40: 72-7

44. Titier K, Girodet PO, Verdoux H, Molimard M et al. Atypical antipsychotics: from potassium channels to torsade de pointes and sudden death. Drug Safety 2005;28(1):35-51

45. Haddad PM, Sharma SG. Adverse effects of atypical antipsychotics : differential risk and clinical implications. CNS Drugs 2007; 21(11):911-936

46. Ray WA, Chung CP, Murray KT et al. Atypical antipsychotic drugs and the risk of sudden cardiac death. NEJM. 2009;360(3):225-35

47. Vieweg WV, Wood MA, Fernandez A. Proarrhythmic risk with antipsychotic and antidepressant drugs: implications in the elderly. Drugs Aging. 2009;26(12):997-1012

48. Poluzzi E, Raschi E, Moretti U, De Ponti F. Drug-induced torsades de pointes: data mining of the public version of the FDA Adverse Event Reporting System (AERS). Pharmacoepidemiol Drug Saf. 2009 Jun;18(6):512-8.

49. Meyer-Massetti C, Vaerini S, Rätz Bravo AE et al. Comparative safety of antipsychotics in the WHO pharmacovigilance database: the haloperidol case. Int J Clin Pharm. 2011 Oct;33(5):806-14

50. Tiihonen J, Lönnqvist $J$, Wahlbeck $W$ et al. 11-year follow-up of mortality in patients with schizophrenia: a population-based cohort study (FIN11 study). Lancet 13 July 2009. DOI:10.1016/S0140-6736(09)60742-X

51. US FDA. Information for Healthcare Professionals: Conventional Antipsychotics. Available via URL: http://www.fda.gov/drugs/drugsafety/postmarketdrugsafetyinformationforpatientsandproviders/uc m124830.htm [Accessed 20 September 2012]

52. Lieberman JA, Stroup TS, McEvoy JP et al. Effectiveness of antipsychotic drugs in patients with chronic schizophrenia. N Engl J Med 2005; 353:1209-1223

53. Lieberman JA, Stroup T. Commentary - The NIM H-CAT IE Schizophrenia Study: What did we learn? Am J Psychiatry 2011; 168:770-5

54. Berkowitz RL, Patel U, Ni Q, Parks JJ, Docherty JP. The impact of the Clinical Antipsychotic Trials of Intervention Effectiveness (CATIE) on prescribing practices: an analysis of data from a large midwestern state. J Clin Psychiatry. 2012; 73(4):498-503. Epub 2011 Dec 13

55. Komossa K, Rummel-Kluge $\mathrm{C}$, Hunger $\mathrm{H}$ et al. Olanzapine versus other atypical antipsychotics for schizophrenia. Cochrane Database of Systematic Reviews 2010, Issue 3. Art. No.: CD006654. DOI: 10.1002/14651858.CD006654.pub2

56. Komossa K, Rummel-Kluge C, Schwarz S et al. Risperidone versus other atypical antipsychotics for schizophrenia. Cochrane Database of Systematic Reviews 2011, Issue 1. Art. No.: CD006626. DOI: 10.1002/14651858.CD006626.pub2

57. Hargreaves WA, Gibson JP. Effectiveness and cost of risperidone and olanzapine for schizophrenia: a systematic review. CNS Drugs 2005; 19: 393-410

58. Heres S, Davis J, Maino K, et al. Why olanzapine beats risperidone, risperidone beats quetiapine, and quetiapine beats olanzapine: an exploratory analysis of head-to-head comparison studies of second-generation antipsychotics. Am J Psychiatry 2006; 163: 185-94

59. Essock SM, Covell NH, Davis SM, Stroup TS et al. Effectiveness of switching antipsychotic medications. Am J Psychiatry. 2006; 163(12): 2090-5

60. Rosenheck RA, Davis S, Covell N et al. Does switching to a new antipsychotic improve outcomes? Data from the CATIE Trial. Schizophr Res. 2009; 107(1):22-9

61. Magnus A, Carr V, Mihalopoulos C, et al. Assessing cost-effectiveness of drug interventions for schizophrenia. Aust N Z J Psychiatry 2005; 39: 44-54

62. Glick ID, Stekoll AH, Hays S. The role of the family and improvement in treatment maintenance, adherence, and outcome for schizophrenia. J Clin Psychopharmacol. 2011;31:82-5.

63. Healy DJ, Taylor S, Goldman M, Barry K, Blow F, Milner KK. Clinical equivalence of generic clozapine. Community Ment Health J 2005; 41(4): 393-8 
64. Alessi-Severini S, Honcharik PL, Simpson KD Eleff MK, Collins DM. Evaluation of an interchangeability switch in patients treated with clozapine: A retrospective review. J Clin Psychiatry 2006; 67(7): 1047-54

65. Paton C. Generic clozapine: outcomes after switching. Br J Psychiatry 2006; 89: 184-5

66. Bazire S, Burton V. Generic clozapine in schizophrenia: what is all the fuss about? Pharmaceutical Jn 2004; 173: 720-1

67. Khorana N, Maphanta S, Lohitnavy O, Srichaiya A, Sayasathid J. Comparative pharmacokinetics and bioequivalence of two tablet formulations of $2 \mathrm{mg}$ risperidone in healthy Thai male volunteers. Int J Clin Pharmacol Ther. 2011; 49:409-14

68. Correl C, Carbon M. Brand vs. generic psychotropic medication. Is one better than the other? Available via URL: https://www.nwpmd.com/LinkClick.aspx?fileticket=vr6K7kfBUfc\%3D\&tabid=342

69. Desmarais JE, Beauclair L, Margolese HC. Switching from brand-name to generic psychotropic medications: a literature review. CNS Neurosci Ther. 2011;17:750-60. doi: 10.1111/j.17555949.2010.00210.x. Epub 2010 Nov 30.

70. Moon J, Flett A, Godman B, Grosso A, Wierzbicki A. Getting better value from the NHS drug budget. BMJ 2011; 342: 30-32

71. WHO Model List of Essential Medicines and developed countries: a comparison with the Lothian Joint Formulary. WHO Drug Information 2006; 20:73-7

72. Lothian Formulary. Available via URL: http://www.lj..scot.nhs.uk/LothianJointFormularies/Adult/4.0/4.2/4.2.1/(a)/Pages/default.aspx

73. Holden J. Hawthorne effects and research into clinical practice. Jn Evaluation Clin Practice 2001; 7; 65-70

74. Konstantinou G. Pragmatic trials: how to adjust for the 'Hawthorne effect'? Thorax 2011;-:1. doi:10.1136/thoraxjnl-2011-200657

75. Trietsch J, van der Weijden $\mathrm{T}$, Verstappen $\mathrm{W}$ et al. A cluster randomized controlled trial aimed at implementation of local quality improvement collaboratives to improve prescribing and test ordering performance of general practitioners: Study Protocol. Implementation Science 4:6 doi:10.1186/1748-5908-4-6 (2009)

76. Verstappen WHJM, Weijden T van der, ter Riet G, Grimshaw J, Winkens R, Grol R. Block design allowed for control of the Hawthorne effect in a randomized controlled trial of test ordering. Journal of Clinical Epidemiology 2004, 57:1119-1123

77. Godman B. Actions to improve the efficient and safe use of drugs: what can we learn from international experiences? 8th Conference of Discussion of Pharmaceutical Spending on Health Managers and Their Impact on Sustainability of the System and 6th Conference of Debate on the Effectiveness and Safety in the Use of Drugs http://www10.gencat.cat/catsalut/archivos/jornades/farmacia/8a/Conferencia inaugural Godman. pdf [Accessed 19 September 2012]

78. World Health Organisation (WHO) Guidelines for ATC classification and DDD assignment 2009. Oslo: WHO Collaborating Centre for Drug Statistics Methodology. www.whocc.no [Accessed 5 March 2012]

79. World Health Organization (WHO). Introduction to Drug Utilisation Research. WHO International Working Group for Drug Statistics Methodology, WHO Collaborating Centre for Drug Statistics Methodology, WHO Collaborating Centre for Drug Utilization Research and Clinical Pharmacological Services. ISBN 924156234 X (NLM classification: WB 330) Available via URL: http://www.who.int/medicines/areas/quality safety/safety efficacy/Drug\%20utilization\%20researc h.pdf [Accessed 3 March 2012]

80. Asenjo Lobos C, Komossa K, Rummel-Kluge C, Hunger H, Schmid F, Schwarz S, Leucht S. Clozapine versus other atypical antipsychotics for schizophrenia. Cochrane Database Syst Rev. 2010 Nov 10;(11):CD006633.

81. Leucht S, Heres S, Kissling W, Davis JM. Evidence-based pharmacotherapy of schizophrenia. Int J Neuropsychopharmacol. 2011 Mar;14(2):269-84. Epub 2011 Jan 6.

82. Raja M. Clozapine safety, 35 years later. Curr Drug Saf. 2011 Jul;6(3):164-84

83. Vlahovic-Palcevski V, Gantumur M, Radosevic N et al. Coping with changes in Defined Daily Dose in longitudinal drug consumption databases. Pharm World Sci 2010; 32:125-9

84. McDowall, D, McCleary, R, Meidinger, EE, Hay, RA (1980) Interrupted time series analysis. In: Sage University Papers Series on Quantitative Applications in the Social Sciences, 07-021. Thousand Oakes, CA: Sage Publications Inc. 
85. Ross-Degnan D, Soumerai SB, Fortess EE, Gurwitz JH (1993) Examining product risk in context. Market withdrawal of zomepirac as a case study. Journal of the American Medical Association, 270, 1937-1942.

86. Durbin J, Watson GS. Testing for serial correlation in least square regression. Biometrika 1951; 37, 409-428.

87. Brennan $P$, Croft $P$. Interpreting the results of observational research: chance is not such a fine thing. BMJ 1994; 309: 727-730.

88. Vogler S, Zimmermann N, Leopold C, de Joncheere K. Pharmaceutical policies in European countries in response to the global financial crisis. Southern Med Review. 2011;4(2):22-32.

89. Maher AR, Maglione M, Bagley S, Suttorp M et al. Efficacy and comparative effectiveness of atypical antipsychotic medications for off-label uses in adults: a systematic review and metaanalysis. JAMA. 2011 Sep 28;306:1359-69

90. Scottish Quality Prescribing Initiative 2012. Available via URL: www.sehd.scot.nhs.uk/pca/PCA2012(M)08.pdf [Accessed 25 May 2012]

91. Chue $P$, Chue J. The cost-effectiveness of risperidone long-acting injection in the treatment of schizophrenia. Exp Re. Pharmacoecon Outcome Res 2012; 12:259-69

92. Lambert T, Emmerson B, Hustig $\mathrm{H}$. Long acting risperidone in Australian patients with chronic schizophrenia: 24-month data from the e-STAR database. BMC Psychiatry 2012, 12:25

93. Willis M, Svensson M, Löthgren M, Eriksson B et al. The impact on schizophrenia-related hospital utilization and costs of switching to long-acting risperidone injections in Sweden. Eur J Health Econ. 2010;11(6):585-94.

94. Rosenheck RA, Barnett PG, Hicks P, Krystal JH, Lew R et al. Cost and cost-effectiveness in a randomized trial of long-acting risperidone for schizophrenia. J Clin Psychiatry. 2012;73(5):696702.

95. Covell NH, McEvoy JP, Schooler NR et al. Effectiveness of switching from long-acting injectable fluphenazine or haloperidol decanoate to long-acting injectable risperidone microspheres: an open-label, randomized controlled trial. J Clin Psychiatry. 2012;73(5):669-75

96. Taylor D, Fischetti C, Sparshatt A, Thomas A, Bishara D, Cornelius V. Risperidone long-acting injection: a 6-year mirror-image study of healthcare resource use. Acta Psychiatr Scand. 2009;120(2):97-101

97. Pechlivanoglou P, Vehof J, van Agthoven M, de Jong-van den Berg LT, Postma MJ. Diffusion of a new drug: a comparative analysis of adoption, treatment complexity, and persistence of risperidone long-acting injectable therapy in the Netherlands. Clin Ther.;32(1):108-18

98. Gaebel W, Schreiner A, Bergmans $P$ et al. Relapse prevention in schizophrenia and schizoaffective disorder with risperidone long-acting injectable vs quetiapine: results of a longterm, open-label, randomized clinical trial. Neuropsychopharmacology. 2010; 35(12):2367-77 